\title{
Using life cycle assessment to compare the environmental performance of electricity generation technologies in Ecuador: fuel oil in internal combustion engines vs. fuel oil in steam power plants
}

\author{
A. D. Ramirez ${ }^{1}$, A. J. Boero ${ }^{1,2}$ \& A. M. Melendres ${ }^{1,2}$ \\ ${ }^{I}$ Escuela Superior Politécnica del Litoral, ESPOL, \\ Facultad de Ingeniería en Mecánica y Ciencias de la Producción, \\ Campus Gustavo Galindo, Ecuador \\ ${ }^{2}$ National Institute of Energy Efficiency and Renewable Energy, \\ INER, Ecuador
}

\begin{abstract}
Ecuador currently has a balanced electricity generation mix between hydropower and thermal power. An important hydropower capacity expansion is expected in the near future. However, during peak demand, thermal power will always be required. Ecuador main fossil fuels used in electricity generation are fuel oil and natural gas. Fuel oil is used mainly in two types of electricity generation technologies: internal combustion engines and steam power plants.

Life cycle assessment (LCA) is a methodological framework used in academia and business to evaluate or compare the environmental performance of products and services. LCA can support decision making at different levels. LCA involves the compilation of environment and resource relevant inflows and outflows throughout the entire life cycle of a product or service. The life cycle of a product involves the extraction of raw materials, several stages of processing, production, use and, end-of-life.

LCA was used to compare the environmental performance of electricity derived from fuel oil in internal combustion engine power plants vs. electricity derived from fuel oil in steam power plants in Ecuador. Life cycle impact assessment results indicate that the electricity generated in internal
\end{abstract}


combustion engine power plants has a lower environmental burden for most impact categories considered.

Keywords: LCA, climate change, thermal, fossil fuels.

\section{Introduction}

Over the past decades, industrialized countries have experienced economic growth at the expense of the environment and their communities. Nowadays, a similar situation still exists, in particular in emerging markets as China and India; and also at some extent in developing countries. These environmental and social impacts, the result of the inefficient use of resources, have a global scale in some cases; for example climate change.

The main effects of climate change are global temperature rise and sea level rise. The current global warming trend is the consequence of human activities, such as deforestation, land use changes, agriculture and combustion of fossil fuels (NASA [1]). The burning of fossil fuels, for transport or electricity generation, has as main product the emission of carbon dioxide, water vapour and other gases such as nitrous oxides. These gases, among others like methane and chorofluorocarbons ( $\mathrm{CFCs}$ ), are the main contributors to the greenhouse effect.

At the end of 2013, the National Interconnected Electric System (NIE), which comprises $90 \%$ of the Ecuadorian electric sector, had a total capacity of $5.1 \mathrm{GW}$; of which $44 \%$ was hydropower and $42 \%$ thermal using fossil fuels. In terms of electricity generation, during the past five years the share of thermal power has ranged between $30 \%$ and 50\% (ARCONEL [2]); which depends, among other things, on meteorology conditions in the region where the hydropower plants are located. There are three type of thermal generation technologies in Ecuador: steam power, gas turbine and internal combustion engines (ICE), and the main fuels used are: fuel oil, natural gas and diesel; being fuel oil the most used $(24 \%$ of the electricity in the NIE came from steam power and ICE based on fuel oil in 2012) [2]. In the next years there will be an important expansion of the hydropower capacity, however thermal power generation will remain as a main contributor during peak demand or times of drought; and with that, their associated impacts will be important to consider.

In order to evaluate and quantify the potential environmental impacts of any product or technology, and in particular those related with electricity generation, there is a mature tool known as life cycle assessment (LCA). LCA has been used to study the electricity production in the majority of industrialized countries as well as to assess the impacts of different generation technologies [3-9].

Considering that electricity is fundamental to the development of a country, and knowing that it is important to have representative life cycle inventories to the Ecuadorian conditions in order to carry out LCA studies, the goal of this work is to compare the life cycle impacts of the use of fossil fuel for electricity generation in steam power plants and internal combustion engine power plants. 


\section{Methods}

\subsection{Goal and scope definition}

In the goal definition is where the objective, reasons and audience of an LCA are defined. The objective of this study is to quantify and compare the environmental burden of electricity produced by steam power plants using fuel oil versus electricity produced by internal combustion engine power plants using fuel oil.

The results of this study can serve to incorporate environmental criteria in the definition of policies regarding the investment in expansion of fossil fuel generation capacity in the country. It is expected that, Ecuadorian policy makers, related ministries, governmental organizations related with planning and control of the electric sector, companies involved in generation of electricity, and the scientific community, will be the audience for the study.

In the scope definition, is where the modelling requirements are defined, including the functional unit and the system boundaries regarding natural system, geography and temporal framework. The functional unit is the quantification of the service or function provided by the studied system. For this study, the functional unit is defined as " $1 \mathrm{kWh}$ of net electricity delivered to the National Transmission System".

The system boundaries of the study are presented in Figure 1. The system includes: the extraction, refining and logistics of fuel; the production of chemicals; the manufacturing of the parts and construction of the power plant; the waste and wastewater treatment; and the power plant operation. The year for data collection is 2012, as was the year for which an entire set of data was available. All the power plant operation data is taken from power plants in Ecuador.

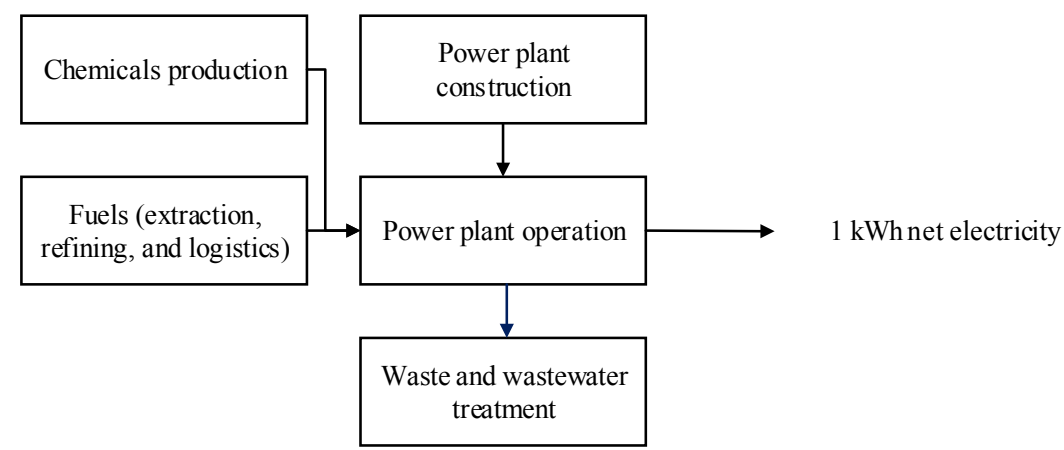

Figure 1: Generic system boundaries for both technologies.

\subsection{Life cycle inventory}

The life cycle inventory is the compilation of product and natural in-flows and out-flows of each process in the studied system. Both, primary and secondary data was used to compile the life cycle inventory. 
Primary data for the operation process of each technology (Table 1) were compiled for both steam power plants and internal combustion engine power plants. Data sources included environmental compliance and monitoring reports of each power plant and personal communication with plant staff. Data was derived from three steam power plants and two internal combustion engine power plants in Ecuador. Flows were averaged for each technology and quantified according to the functional unit.

Table 1: Data compiled for the operation of each technology.

\begin{tabular}{|l|l|l|}
\hline Inputs & Product flows & Fuels (primary and secondary) \\
& & Chemicals \\
\cline { 3 - 3 } & & Water \\
\cline { 3 - 3 } & & Power plants \\
\hline Outputs & \multirow{2}{*}{ Product flows } & Electricity \\
& & Wastewater \\
& & Solid waste \\
\cline { 3 - 3 } & & Hazardous waste \\
\hline & Natural flows & Air pollutants \\
\hline
\end{tabular}

Product and natural flows associated with: the extraction, refining and logistics of fuel; the production of chemicals; the manufacturing of the parts and construction of the power plant; the waste and wastewater treatment; were derived from the Ecoinvent [10] life cycle inventories database.

\subsection{Life cycle impact assessment}

The life cycle impact assessment is the part of a LCA study where the result for the life cycle inventory, the natural flows of each process, are transformed into life cycle impact assessment category indicator results. This is performed using characterization models.

The characterization models included in the CML-IA (baseline) methodology [11] were used in this study. Six life cycle impact categories were considered: Abiotic Depletion (Fossil Fuels), Global Warming, Ozone Layer Depletion, Photochemical Oxidation, Acidification and Eutrophication.

Simapro 8.0 [12] software package was used to perform the life cycle inventory and impact assessment calculations.

\section{Results}

\subsection{Comparison of environmental performance}

The results are presented at impact assessment level. As it is a comparative study, the result for each impact category for the technology with the highest results is considered $100 \%$ and the result for the other technology is calculated as the respective percentage (Figure 2). 
Photochemical oxidation

Ozone layer depletion

Global warming

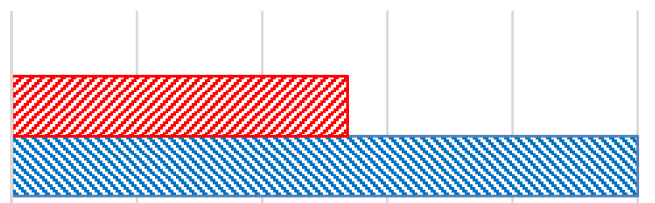

Acidification
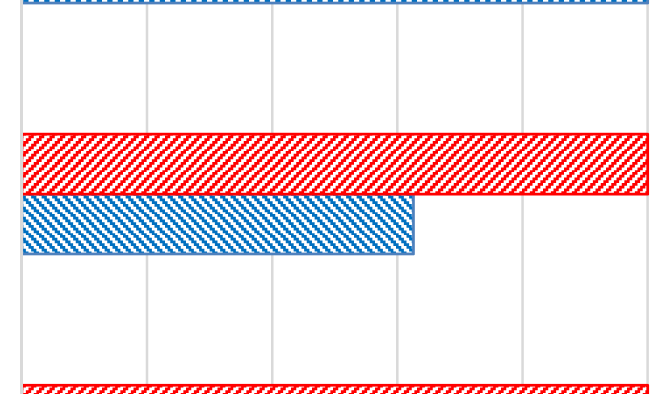

Abiotic depletion (fossil fuels)
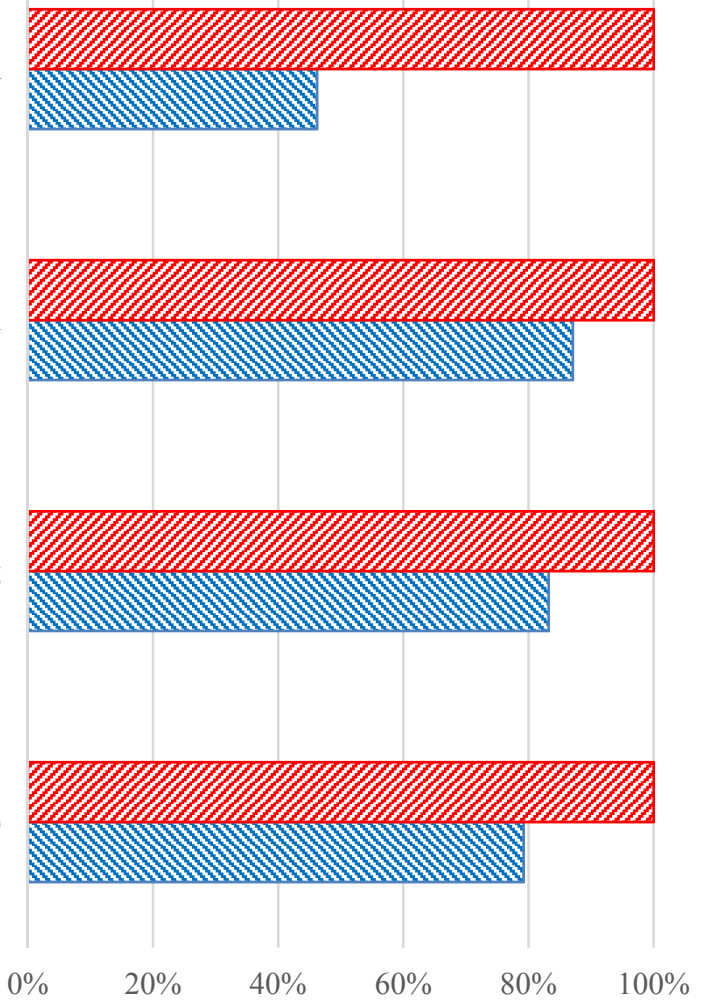

aFO-ST $\mathbf{a F O}-\mathrm{ICE}$

Figure 2: Relative impact categories indicator results for $1 \mathrm{kWh}$ of electricity from FO-ICE and FO-ST. 
The electricity produced in internal combustion engine power plants using fuel oil has lower environmental impact results for five of the considered categories: abiotic depletion (79\% of the result for steam power plants), global warming (83\%), ozone later depletion (87\%), photochemical oxidation $(46 \%)$, and acidification (63\%), in comparison to the electricity produced in steam power plants using fuel oil. In the case of the impact category eutrophication, the electricity produced in steam power plants has a lower result $(54 \%$ of the result for internal combustion engine power plants).

\subsection{Contribution analysis}

Figure 3 presents the contribution analysis for each impact category for both technologies under study. The power plant operation is the highest contributor to four impact categories: eutrophication, acidification, photochemical oxidation, and global warming, for both technologies. These impact categories are highly associated with emissions during combustion of fossil fuels which is part of the power plant operation. The production of the fuel (including extraction, refining, and logistics) is the main contributor to the impact categories, ozone layer depletion, and abiotic depletion (fossil fuels), for both technologies.

The contribution analysis (Fig. 3) also allows to understand the differences in impact category results for both technologies. In the case of eutrophication, the emissions associated with the combustion during operation of the internal combustion engine power plant result in a higher contribution and result for this technology when compared to steam power plants. This is mainly due to the higher emissions of nitrogen oxides in the flue gases of the internal combustion engine power plant.

Acidification and photochemical oxidation are also impact categories mostly associated with emissions during combustion; however in this case the emissions associated with the combustion during operation of the steam power plant result in a higher contribution for this technology when compared to internal combustion engine power plants. This is mainly due to the higher emissions of sulphur dioxide in the flue gases of the steam power plant.

Ozone layer depletion is mostly associated with emissions during fuel production and refining. Electricity generated in steam power plants is associated with a higher impact category result than that generated in internal combustion engine power plants. Ozone layer depletion is an impact category which depends on the emissions of organic compounds such as chlorofluorocarbon and chlorodifluoromethane.

Global warming is mostly associated with the power plant operation, and in particular with the emission of carbon dioxide during the combustion of fossil fuels. However the contribution of fuel production and refining is not negligible.

Abiotic depletion is mostly associated with fuel production, as that is the phase where the abiotic depletion takes place. As in this case the internal combustion engine power plants consume lesser fuel oil per $\mathrm{kWh}$ produced in comparison to steam power plants. 


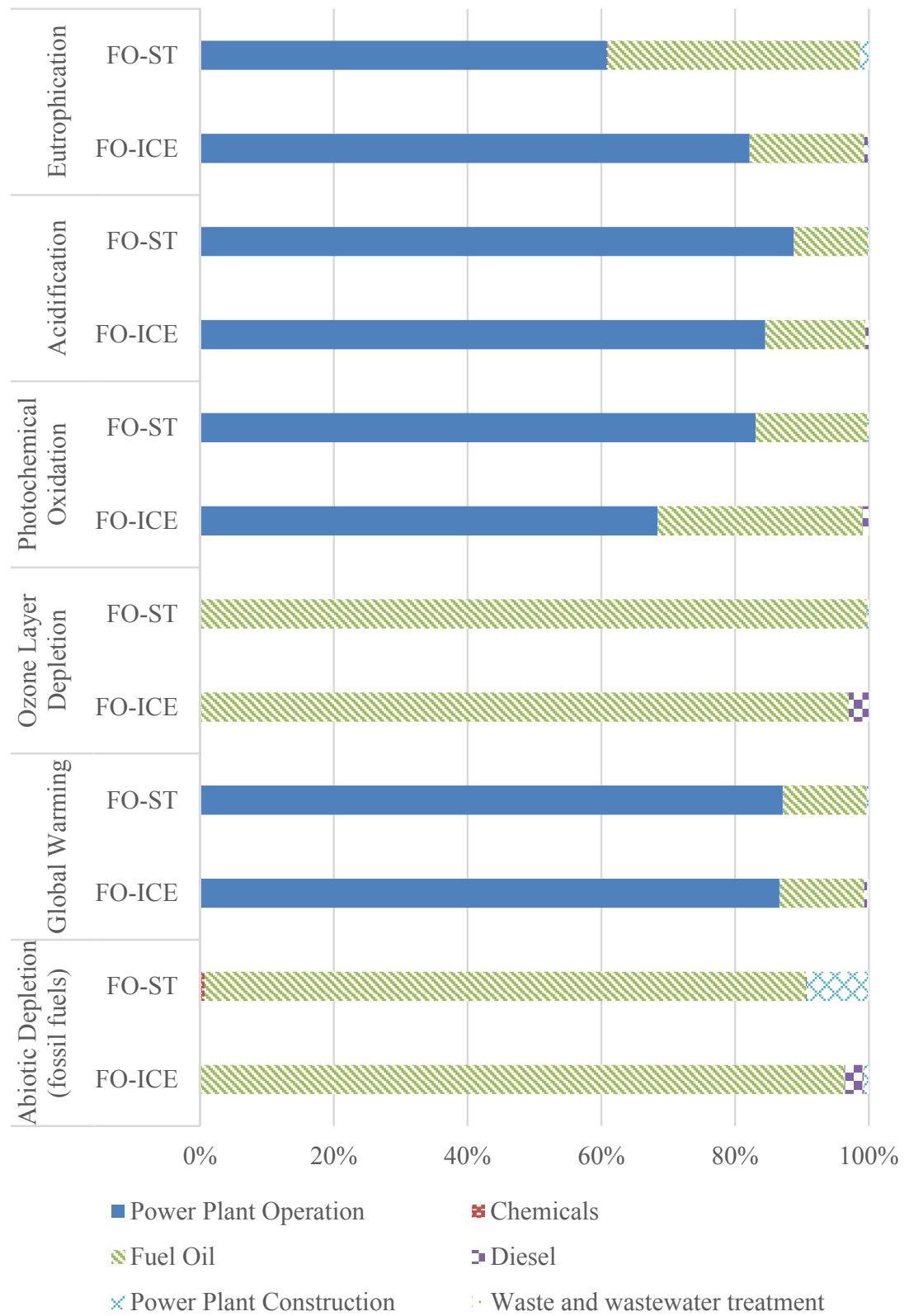

Figure 3: Contribution analysis for each impact category for both technologies. 


\section{Discussion}

To compare the environmental performance of electricity produced by steam power plants using fuel oil versus electricity produced by internal combustion engine power plants using fuel oil, requires a comprehensive assessment. The electricity produced in internal combustion engine power plants using fuel oil has lower environmental impact results for five of the considered categories and higher for only one.

While these results indicate that it is better to use the fuel oil in internal combustion engine power plants than in steam power plants. It should be taken into account that the technology used in the steam power plants studied is considerably older that the technology used in internal combustion engines. The investment in new capacity for thermal electricity generation in Ecuador in the latest years has been directed toward internal combustion engine power plants, mainly because they are adequate for covering peak demand in contrast with steam power plants.

For the power plants under study, the steam power plants use more fuel per $\mathrm{kWh}$ produced than internal combustion engine power plants. More modern steam power plants with combined cycle have higher efficiency than those currently used in Ecuador.

For current technologies used in Ecuador, internal combustion engines show a better performance for most impact categories considered. However a decision on investment will have to take into account that current state of the art of steam power plant technology. It should be noted that is the objective is to establish a power plant to cover peak capacity, the suitability of technology for this function should be also included in the decision.

\section{Conclusions}

Life cycle assessment has been used to compare the environmental performance of electricity generated by two thermal power plant technologies: internal combustion engines and steam power. The study has been based on power plants currently in operation in Ecuador. The results indicate that internal combustion engines have a better performance for five of the considered categories: Abiotic depletion, Global warming, Ozone later depletion, photochemical oxidation, and acidification. Whiles in the case of eutrophication the opposite occurs. Efficiency of internal power plants is highest than current steam power plants. This is associated with the age of technologies used. To use the results to incorporate environmental criteria in the decision on which technology to invest, should also consider newer technologies for steam power plants.

\section{Acknowledgements}

This paper is based on work founded by National Secretary of Planning and Development of Ecuador (SENPLADES). The authors would like to thank the Electricity Corporation of Ecuador (CELEC EP), Agency of Regulation and 
Control of Electricity (ARCONEL, formerly known as the National Council of Electricity, CONELEC), National Energy Control Center (CENACE) and ELECTROQUIL S.A. for the information provided.

\section{References}

[1] NASA, "Global Climate Change: Vital Signs of the Planet," 2015. Online, http://climate.nasa.gov/

[2] ARCONEL, "SISDAT Publico," 2015. Online. http://www.conelec.gob.ec /contenido.php?cd $=115 \& \mathrm{l}=1$

[3] Rafaschieri A., Rapaccini M., and Manfrida G., "Life Cycle Assessment of electricity production from poplar energy crops compared with conventional fossil fuels," Energy Convers. Manag., vol. 40, no. 14, pp. 1477-1493, 1999.

[4] Dubreuil A., "Inventory for energy production in Canada," Int. J. Life Cycle Assess., vol. 6, no. 5, pp. 281-284, 2001.

[5] Coltro L., Garcia E. E. C., and Queiroz G. D. C., "Electric Energy System in Brazil LCA Case Studies Life Cycle Inventory for Electric Energy System in Brazil," vol. 8, no. 5, pp. 290-296, 2003.

[6] Lee K.-M., Lee S.-Y., and Hur T., "Life cycle inventory analysis for electricity in Korea," Energy, vol. 29, no. 1, pp. 87-101, 2004.

[7] Curran M. A., Mann M., and Norris G., "The international workshop on electricity data for life cycle inventories," J. Clean. Prod., vol. 13, no. 8, pp. 853-862, 2005.

[8] Ribeiro F. D. M. and da Silva G. A., "Life-cycle inventory for hydroelectric generation: a Brazilian case study," J. Clean. Prod., vol. 18, no. 1, pp. 44-54, 2010.

[9] Santoyo-Castelazo E., Gujba H., and Azapagic A., "Life cycle assessment of electricity generation in Mexico," Energy, vol. 36, no. 3, pp. 14881499, 2011.

[10] Swiss Centre for Life Cycle Inventories, "Ecoinvent database," 2014.

[11] Institute of Environmental Sciences, "CML-IA Methodology." 2015.

[12] PRé Consultant, "SimaPro.” 2014. 